\title{
Lied contre chanson contre poème : sur Wolf Biermann et « Frühling auf dem Mont-Klamott »
}

Lied vs Chanson vs Gedicht: über Wolf Biermann und „Frühling auf dem MontKlamott"

Lied vs. Chanson vs. Poem: On Wolf Biermann and "Frühling auf dem MontKlamott"

Philippe Marty

\section{OpenEdition}

\section{Journals}

Édition électronique

URL : https://journals.openedition.org/ceg/7940

DOI : $10.4000 /$ ceg. 7940

ISSN : 2605-8359

\section{Éditeur}

Presses Universitaires de Provence

\section{Édition imprimée}

Date de publication : 1 mai 2013

Pagination : 69-81

ISBN : 0751-4239

ISSN : 0751-4239

\section{Référence électronique}

Philippe Marty, "Lied contre chanson contre poème : sur Wolf Biermann et « Frühling auf dem Mont-

Klamott » », Cahiers d'Études Germaniques [En ligne], 64 | 2013, mis en ligne le 02 janvier 2020, consulté le 02 juin 2021. URL : http://journals.openedition.org/ceg/7940 ; DOl : https://doi.org/10.4000/ceg. 7940 


\title{
Lied contre chanson contre poème : sur Wolf Biermann et « Frühling auf dem Mont-Klamott»
}

\author{
Philippe MARTY
}

Université Montpellier 3

\section{" Chanteur-poète "; « Auftreten 》 (un chanteur-poète entre en scène)}

Je propose, pour réfléchir à la notion de contre-culture, l'exemple d'une chanson de 1966, «Frïhling auf dem Mont-Klamott», de Wolf Biermann, sur le disque Chausseestraße 131. Avant de parler précisément de l'exemple, il y aurait beaucoup de questions à examiner concernant la ou une « contreculture » dans le contexte de la RDA des années 1960 (celles qui suivent les conférences de Bitterfeld') et du débat sur le lyrisme et sur le «moi lyrique » dans la revue Forum en 1966 à l'occasion de la publication de l'anthologie In diesem besseren Land ${ }^{2}$. Beaucoup de questions aussi sur la place, dans le Berlin-Est de ces années-là, de Wolf Biermann chanteur et poète (plutôt que « chanteur-poète », qui vaut pour le contexte français). Biermann est poète et traité comme tel dans les histoires de la littérature de la RDA ou de la poésie allemande (il appartient à la génération de Sarah Kirsch, Volker Braun ou Reiner Kunze ; mais seul Volker Braun est représenté dans l'anthologie de 1966) - et chanteur, c'est-à-dire auteur, compositeur et interprète de chansons, et guitariste.

En tant que quoi représenterait-il quelque chose de la contre-culture ? En 1965, c'est après la publication de son recueil de poèmes Die Drahtharfe (La

1 Pour mémoire, la première de ces conférences sur la politique culturelle de la RDA a licu le 24 avril 1959. Elle réunit cnviron 150 ćcrivains et 300 ouvricrs sous le mot d'ordre "Greif zur Feder Kumpel! Sozialistische Nationalkultur braucht dich !» (Prends la plume camarade ! La culture socialiste a besoin de toi !). Walter Ulbricht veut ainsi encourager les collaborations entre les artistes et le monde du travail - usines et brigades de production -, afin que sc constitue unc culture ouvric̀re authentique, représentéc par des écrivains-ouvricrs. La scconde conférenec se tient les 24-25 avril 1964.

2 Anthologie publiće par Adolf Endler et Karl Mickel ; son titre (qui ne doit sans doute pas se lire comme un trait d'ironic) cite un vers de Heinz Czechowski. 
harpe de fil de fer) et de son premier disque, Wolf Biermann (Ost) zu Gast bei Wolfgang Neuss (West) [Wolf Biermann (Est) invité par Wolfgang Neuss (Ouest)] que Biermann se voit « interdit de se produire sur scène et de publier » par les autorités de la RDA (« Auftritts- und Puklikationsverbot»). L'interdiction de se produire sur scène concerne le chanteur, semble-t-il. Un poète peut certes monter sur scène pour dire ses poèmes devant un public (Wolf Biermann l'a fait dès 1962), mais on ne dit pas, comme on le dit en français pour un chanteur interprétant pour la première fois une chanson en concert, qu'il «crée » le poème. Dans l'image du «Auftreten » (mettre le pied sur les planches, éventuellement taper du pied - comme le fait parfois Biermann en chantant -, se présenter, faire son apparition, ne pas rester caché, proposer ses services, son expertise, son engagement), il y a quelque chose sans doute qui distingue poète et chanteur, et quelque chose aussi à partir de quoi il serait possible de réfléchir à une notion comme la contreculture, en tant qu'elle nécessite et implique l'ici et le maintenant de la « performance » par rapport au caractère idéal et désincarné de la culture savante : être cultivé, ce serait justement s'abstraire, et s'élever au-dessus de la contingence concrète de l'ici et du maintenant, rencontrer de l'absent (du texte, du sens) et de l'ancien.

\section{Chanson : allégeance, parodie}

Mais la question préalable - avec laquelle je voudrais rester un peu - est celle de savoir si la chanson comme genre, le genre ou le médium chanson en tant que tel, appartient à la contre-culture. La question n'a pas du tout le même sens si on la pose à partir du mot français «chanson » ou du mot allemand «Lied» (ou de l'anglais «song »). Dans la culture française, la chanson constitue un genre dont la tradition court à côté de la tradition et de l'histoire de la poésie, elle est l'autre de la poésie. Béranger (que Biermann nomme comme un de ses modèles) est au XIX ${ }^{\mathrm{e}}$ siècle l'autre grand poète français, aussi célèbre que Hugo. Béranger est aujourd'hui absent de 1'histoire de la poésie française, il n'est cité dans aucune anthologie, sauf justement dans certaines anthologies allemandes de la poésie française. La relation entre les deux voisines, chanson et poésie, est, au $\mathrm{XX}^{\mathrm{e}}$ siècle encore, d'allégeance : tous les « chanteurs-poètes" français, à partir des années 1930 saluent et imitent les poètes, et spécialement la triade Baudelaire-Rimbaud-Verlaine. «Chanson à texte », dit-on en français, c'est-à-dire chanson regardant vers la poésie, chanson écrite par des savants qui connaissent les codes de la culture. Les textes de Brassens sont semés de vers parodiant des vers célèbres, comme «[...] La mort, la mort, toujours recommencée » (parodie de Valéry : « La mer, la mer [...]) ou «C'est Psyché tout entière qui vous sautait aux yeux », parodiant Racine ( C'est Vénus tout entière [...]»). Cette chanson est « contre-culturelle», si on veut ici employer le mot, au sens de "parodique ». Elle est un «chant à côté », " parôdos», et on peut dire, en faisant jouer 
toutes les acceptions de la préposition grecque « para », que, dans ce contexte français, la chanson provient de la poésie, se développe auprès d'elle, mais aussi en dehors d'elle, proche mais chassée du foyer savant. Les chanteurs à texte français sont des "héritiers », et la contre-culture, dit Bourdieu, n'est jamais le fait des plus démunis, elle suppose toujours un certain capital culturel. Pierre Dupont, que Baudelaire a salué, ou Brassens, savent ce qu'est une rime pour l'œil ; les rimes du «Chant des ouvriers » sont toutes «pour l'œil » (et le texte de Dupont est métriquement impeccable), elles n'ont rien des rimes approximatives, assonancées, faciles ou délabrées (du type «claire fontaine /...eau si belle ») de la chanson populaire, elles sont un hommage respectueux de la chanson à la poésie, du paysan à l'artiste, du valet au maître.

La " chanson », dans ce sens-là, n'appartient pas à la sous-culture ou à la culture populaire, comme la chanson de variétés, mais elle n'appartient pas non plus à la culture savante. Il y eut une polémique en France, au début des années 60, quand Ferré puis Brassens furent publiés dans la collection de Pierre Seghers, «Poètes d'aujourd'hui » : on aurait fait franchir aux deux chanteurs, illégitimement, une barrière symbolique ; la chanson est certes aux côtés (" para ») de la poésie (comme Sancho aux côtés de Don Quichotte, comme une contre-allée court parallèlement à l'allée principale où vont les cavaliers et les voitures), elle regarde vers la poésie, mais elle ne doit pas pouvoir entrer. Seghers créera d'ailleurs assez vite, pour les chanteurs, une série parallèle, ou « contre-série », intitulée « Poésie et chansons ».

Que cette tradition-là est spécifiquement française se montre au fait que l'allemand a emprunté le mot au français ( das Chanson», distingué de « die Chanson " qui désigne la chanson du Moyen Âge) ; elle implique le plus souvent un auteur-interprète, c'est-à-dire un personnage qui se montre en public («auftritt»), mais qui par ailleurs est « auteur», au sens de : celui qui envoie, à sa place, un produit détaché et autonome (comme le troubadour disant dans l'envoi de sa chanson : « va maintenant, chanson, trouver mon aimée... »). De ce point de vue, l'auteur-interprète appartiendrait à la fois à la contre-culture et à la culture : à la contre-culture parce que son " œuvre» ne vaut que par la présence d'un performateur, ici et maintenant ; à la culture parce que le produit qu'il a élaboré peut aussi se lire et se goûter in absentia, et s'est libéré d'une « praxis » concrète (celle de l'interprète, éventuellement instrumentiste). Brassens est caractéristique de cette double appartenance: interprète gêné sur scène et semblant dire à son public : " ne faites pas attention à moi, mais à mon ouvre seulement, comme si vous la lisiez, et comme si je n'étais pas là ", il est le contraire du militant au sens où le militant nécessairement «y est », « fait » quelque chose comme le soldat fait la guerre, sur le terrain. Non pas que la « chanson» soit foncièrement apolitique ou désengagée, mais sa protestation est le plus souvent d'inspiration individualiste et privée : «Le jour du 14 juillet », dit Brassens (« La mauvaise réputation »), « Je reste dans mon lit douillet» (je m'absente, je ne prends pas part, et non pas : j'organise un contre-défilé). 
Biermann connaît cette tradition de la « chanson "; il a écrit, dès ses débuts, des "chansons » au sens français, et les critiques que les autorités de la RDA ont formulées contre lui sont celles aussi qui ont été adressées, en France vers le milieu des années 50, au Brassens du « Gorille» et de « La mauvaise réputation »: obscénité, anarchisme individualiste, et (ceci ne vaut que pour Biermann évidemment) «opposition de principe au socialisme réel » (« prinzipielle Gegnerschaft zum realen Sozialismus »). «Die grüne Schwemme », par exemple (écrite en 1960 ; elle a été enregistrée aussi par Eva-Maria Hagen, en 1999) est faite pour mériter les reproches d'individualisme, sensualisme, « escapisme » (fuite dans le rêve), romantisme idéaliste, incitation à l'oisiveté, etc.; en voici le texte :

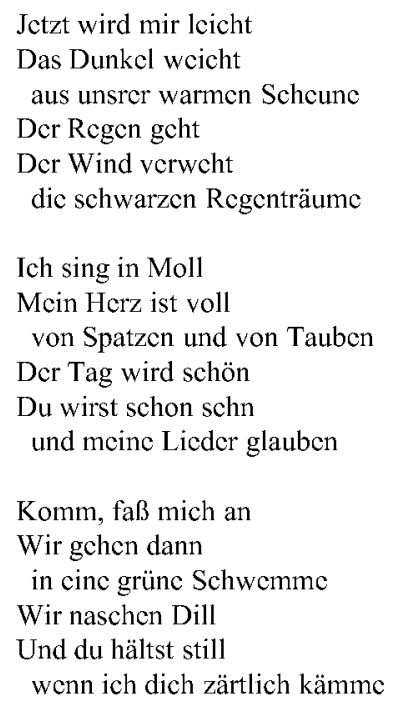

En R.F.A., ce serait une simple chanson d'amour (elle fait partie du disque Liebeslieder, paru en 1975), un peu (et volontairement) mièvre; pour l'idéologie socialiste, elle est doublement inadmissible : elle parle (premier péché) d'une sorte de tristesse et de pessimisme («Dunkel», « Regenträume », etc.) Ensuite : la mélancolie n'est surmontée que par la promenade dans la nature, à deux, un repli dans l'intimité, et dans un lieu appelé, vaguement ou poétiquement, « die grüne Schwemme ». "Grüne Schwemme » est peut-être une référence à Rimbaud, au « Cabaret-Vert » ou à «l'auberge verte" de la «Comédie de la soif ». «Schwemme», c'est le bar, la ginguette, le débit de bière, mais d'abord le point d'eau ou le gué, où viennent boire les chevaux, les vaches. "Aller où boivent les vaches" dit encore Rimbaud dans « Comédie de la soif », c'est-à-dire aller où nul humain ne peut être, former l'image d'un lieu idéal, d'une retraite idyllique, quelque chose d'autre que le paradis socialiste désigné comme atteignable par le Parti. La chanson d'amour, en tant que revendication par l'individu du bonheur privé, est ainsi, dans le contexte de l'édification du socialisme réel, une 
chanson " contre ». Elle revendique le droit au "mode mineur », opposable au " majeur " ou au «cadencé » des chants patriotiques et socialistes, au « Vorwärts zum Sozialismus » ou au « Vorwärts und nie vergessen - die Solidarität » du " Solidaritätslied » de Brecht et Eisler. Elle revendique le droit à l'inaction, à la paresse (la seule action notée, dans le dernier vers, le «kämmen » qui se souvient peut-être de la Loreley de Heine peignant ses cheveux, est purement intime et sensuelle). Non pas que le «moi lyrique » ici se désolidarise et se retire définitivement, mais la chanson dit, mezzo voce, sur le mode rêveur, qu'il doit être possible à chacun, même et surtout dans un État socialiste, de faire parfois retraite et de se tenir coi, de ne plus « en être » momentanément. Le chanteur paraît, " tritt auf », pour exprimer son droit à s'en aller, à disparaître, à soupirer, en public, après un bonheur privé (Biermann ponctue chaque strophe terminée par une espèce de soupir d'aise). En ce sens, Biermann, dans le Berlin-Est des années 60, écrit et chante contre (contre l'activisme embrigadé).

\section{Song : Protest}

Mais Biermann vient aussi d'une autre tradition que celle de la chanson «lyrique » ou «à texte ", qui se fait une place « tout contre » la poésie. Il vient de la tradition du « Bänkelsang », des « Moritaten», complaintes de chanteurs des rues, (dans Chausseestraße, il y a une « Moritat auf Biermann seine Oma Meume in Hamburg »), des "Balladen » (au sens germanique et au sens français : il y a aussi dans Chausseestraße une «Ballade auf den Dichter François Villon ») et des « songs ». Car l'allemand dispose aussi, avec «Lied » et « Chanson », du mot « Song », pour désigner les chansons. Pourquoi le mot anglais a-t-il été emprunté ? Que dit-il de spécifique que ne disent ni le mot allemand ni le mot français ? «song » aujourd'hui s'est propagé pour désigner tout produit chanté provenant du monde anglo-saxon. Mais dans les années 1920, quand il se répand en allemand, il désigne une chanson protestataire (Protestsong) ou révolutionnaire ${ }^{3}$. Ce peut être une chanson traditionnelle adaptée aux revendications du mouvement ouvrier, ou une chanson contestataire écrite par un musicien savant, Hanns Eisler par exemple. « Song » appartiendrait donc à la « contre-culture » de deux façons : le « Song » est populaire, c'est un avatar pour le $\mathrm{XX}^{\mathrm{e}}$ siècle du folksong; il est contestataire, il s'oppose à la culture dominante bourgeoise, il est lié à la lutte des classes. Si le mot s'impose en allemand, c'est en particulier parce que Brecht appelle «Songs » les chansons mises dans ses opéras de 1928 et de 1930, Die Dreigroschenoper et Aufstieg und Fall der Stadt Mahagonny. Le mot « song » s'explique, bien sûr, par le contexte anglais ou américain des deux auvres, mais il s'impose aussi contre « Chanson» et contre «Lied»:

3 Voir le numéro 9 de la Revue Commune (éditée au Temps des Cerises), 1998, intitulé «La chanson protestataire». 
ce qui s'écrit là, dans les années vingt, et dont Biermann est l'héritier (Biermann est, de ce point de vue, le successeur de Ernst Busch) ne peut s'appeler « chanson » si on entend dans le mot français la dimension individualiste et sentimentale, ni non plus «Lied». Qu'est-ce que l'allemand «Lied » fait entendre?

\section{Lied}

«Lied» a une tout autre place dans la culture allemande (et donc dans la contre-culture) que « chanson » et que «song ». «Lied » appartient d'emblée à l'« héritage culturel », plus que « chanson » qui n'a fait partie de l'histoire savante de la littérature française que dans les premiers commencements (chansons de geste, chansons de troubadour) avant d'en être chassé pour passer «à coté » et «contre ». « Lied » désigne, d'une part, un genre savant (Lieder de Schumann, etc.) et le mot, dans ce sens, est emprunté par le français (le français dit également «mélodie »: « une mélodie de Fauré»). Biermann est aussi, à sa façon, et à la guitare, un auteur de « Lieder» dans ce sens : il enregistre en 1979, à l'Ouest, après sa déchéance de la nationalité estallemande ("Ausbürgerung »), le disque Hälfte des Lebens, où il met en musique des poèmes de Lenz, Hölderlin, Brecht, etc., comme si l'exil le privait, pour un temps, de faire entendre une parole propre, à la fois contestataire et intime. Mais, outre cet emploi technique où il désigne un genre, il apparaît, le plus souvent, que "Lied " ne peut se traduire par « chanson », quand il se trouve dans un poème : « Schläft ein Lied in allen Dingen », dit Eichendorff dans le quatrain "Wünschelrute ». Les traducteurs français (par exemple René Lasne) disent ici «chant», jamais «chanson" (peut-être peut-on dire « refrain »). « Chanson» sonnerait «populaire», « chant» est plus noble, et ainsi la hiérarchisation et la lutte des classes entre poésie et chanson (en français) se marquent dans la traduction. "Chant» serait, si on le retraduisait en allemand, « Gesang ». Mais jamais Eichendorff, dans ce vers, n'aurait dit « Gesang ». La paire allemande « Lied / Gesang » ne correspond pas à la paire «chanson / chant». Dans « chant», il peut y avoir, en français, une dimension contre-culturelle, et en tout cas communautaire ou révolutionnaire : des titres comme «Chant des ouvriers» de Pierre Dupont, ou « Chant des partisans », en témoignent. "Le temps des cerises» (que Biermann a traduit et enregistré) est un exemple intéressant : à la fois chanson (au sens décrit plus haut : lyrique, amoureuse, intime) et, par la grâce d'une dédicace, chant révolutionnaire, lié à la Commune. Mais cette opposition chant / chanson ("chant" étant le terme distingué) ne vaut pas pour l'allemand : les Parques, en allemand, chantent un «Lied» (« Lied der Parzen », de Goethe) : " chant» disent unanimement les traducteurs français ; ou, autre effet de l'interdit culturel frappant le mot " chanson », le Buch der Lieder de Heine est toujours en France Le Livre des chants. 
Un dernier exemple, plus récent. Le poème "Fadensonnen » (écrit en 1963), de Paul Celan (paru dans Atemwende, 1967), dit :

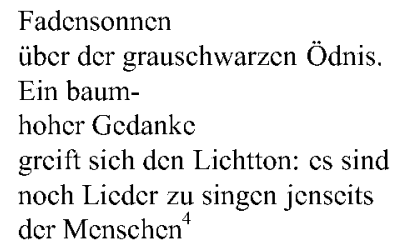

Là où il y a vide, lumière, espace, quelque chose peut s'élever et se faire entendre qui en allemand s'appelle « Lied » (dans l'avant-dernier vers). En français, ce quelque chose céleste ou idéal ne peut s'appeler « chanson ». Jean-Pierre Lefebvre, par exemple, le traducteur, dit : « il y a / encore des chants à chanter au-delà / des hommes ». «Lied » se présente comme un motracine (égal de ce point de vue à «Stein», « Luft», « Baum», etc.) que la langue semble offrir d'elle-même, alors que «chanson » est un mot dérivé, non-premier : un mot que les hommes ont construit. "Lied » est donc plus capable que « chanson » de porter une tradition romantique où la nature chante toute seule, hors ou contre les hommes, et où le chanteur, pour entendre et comprendre le chant (Lied) naturel, se retire de la communauté des hommes : on sort de scène, «Abtritt » au lieu de «Auftritt». Cette ligne romantique incluse dans le mot «Lied », le «faiseur de chansons» (Liedermacher) Wolf Biermann ne la repousse pas, pas plus que Heine ne l'a repoussée. Biermann est "Liedermacher» dans tous les sens du mot «Lied»: au sens où «Lied » peut s'entendre comme un équivalent de " chanson" ou de "song ", et au sens que nous venons de présenter, où «Lied» est un intraduisible; sens solidaire-progressiste-contestataire, sens individualiste-anarchiste, sens romantique. C'est dans tous ces sens que peut se décrire le caractère « contre-culturel» d'une chanson comme «Frühling auf dem Mont-Klamott » dans le contexte du Berlin-Est du milieu des années 60. Voici d'abord le texte de la chanson:

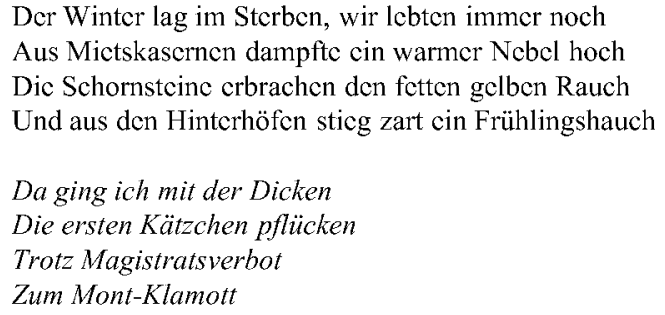

4 Erich Fricd a opposé au poc̀me « anti-humaniste», " anti-solidaire» de Celan cc qu'on peut appeler un «contrc-poème» (Gegengedicht) : «Beim Wicderlesen cincs Gedichtes von Paul Cclan » (Die Freiheit den Mund aufzumachen. 48 Gedichte, 1972) : «[...] Licder der Zukunft / jenscits der Unzeit in dic wir/alle verstrickt sind / Ein Singen jenseits / des für uns Denkbaren / Weit // Doch nicht cin cinziges Lied / jenseits der Menschen ». 


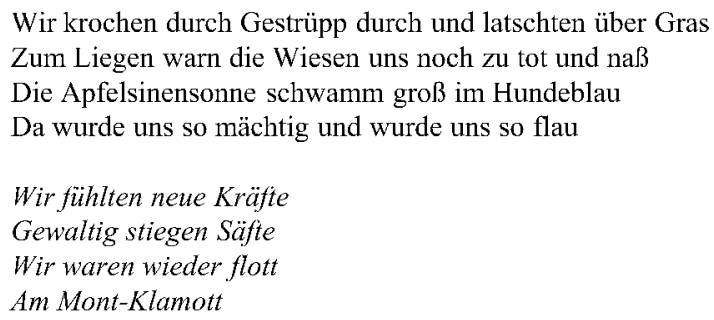

Wir küßten uns im Gehen und küßten uns im Stehn Wir sahn 'ne Menge Menschen und wurden selbst gesehn Ich rollte meine Schöne die steilen Hänge rauf

Sie kreischte, und ich lachte, sie fiel, ich fing sie auf

Mensch, waren das Genüsse!

Uns schmeckten unsre Küsse

Wie Ananaskompott

Am Mont-Klamott

Und als wir oben standen, die Stadt lag fern und tief Da hatten wir vom Halse den ganzen deutschen Mief Ich legte meine Hände auf ihren warmen Bauch

Und sagte: süße Dicke fühlst du den Frühling auch?

Die Tauben und die Spatzen

Die ersten Knospen platzen

Auf Trümmern und auf Schrott

Am Mont-Klamott

Wir saßen auf dem Kehricht vom letzten großen Krieg Die Dicke sprach von Frieden, ich hörte zu und schwieg Wir saßen, bis die Sonne im Häusermeer absoff Sahn zu, wie da der Westen die rote Farbe soff

\author{
Auf Kirchen und auf Schloten \\ Dieselben roten Pfoten \\ Wir dankten Marx und Gott \\ Am Mont-Klamott
}

\title{
Vivant, présent, respirant
}

Beaucoup de choses, à l'écoute, précèdent le premier vers de la chanson : l'enregistrement fait entendre d'abord, et à nouveau à la fin de la chanson, les bruits de la rue. C'est la Chausseestraße, où habitait Biermann. Biermann a enregistré chez lui, avec un micro et un magnétophone de contrebande. Plutôt que de chercher à atténuer l'arrière-plan sonore que captait le microphone, il a choisi au contraire d'ouvrir les fenêtres. Façon de dire : « je descends dans la rue, j'y suis », de dire à la Stasi : «vous pouvez venir me chercher, je ne me cache pas, je me dénonce " (le titre Chausseestraße 131 donne l'adresse de 
l'artiste). Ainsi s'inscrit tout de suite un trait contre-culturel : l'auteur n'envoie pas à sa place son œuvre; il s'expose. C'est comme un « Hier stehe ich und kann nicht anders ». Ici, dans l'appartement privé (montré sur la pochette du disque), le chanteur se distingue (bourgeoisement) de la foule des rues, mais il envoie aussi, par les fenêtres ouvertes, ses chansons au public, et les enregistre au nez et à la barbe des autorités.

Ce qui s'entend aussi au début de la chanson, c'est un sifflotement (celui du merle moqueur : c'est une chanson de printemps) et un grognement d'aise. C'est encore une façon d'affirmer sa présence, sa bonne santé ${ }^{5}$, et de dire : « je suis en vie ». C'est l'inverse de ce que propose «l'envoi » dans une chanson de troubadour: par l'envoi, le troubadour se fait représenter par sa chanson; au contraire, en envoyant d'abord son souffle (sifflotement), le chanteur de la Chausseestraße se pose devant et avant la chanson, la présente et la représente, annonce qu'il ne se retirera pas. C'est parce qu'il est d'abord un individu (en vie, et habitant ici, maintenant) que le chanteur peut s'adresser (à la fois aux autorités et aux passants de la rue). La chanson est ainsi doublement « contre »: elle est réaction individuelle, sensuelle et naturaliste contre l'emprise du régime autoritaire et des directives culturelles, mais aussi réaction solidaire et intellectuelle contre la culture « savante » et « élitiste », dont les œuvres ne sont pas liées à une présence, un souffle et un corps.

Et, dernière chose qui s'entend avant que ne commence la chanson proprement dite : Wolf Biermann annonce, comme un «Bänkelsänger », un bateleur à la parade, ou comme s'il était sur scène (alors qu'il enregistre dans son appartement), la chanson en lançant (voix parlée) : " Das ist unser Frühling auf dem Mont-Klamott! ». Le « notre » (« notre printemps ») se comprend dans un sens érotique (ma compagne et moi-même, l'éveil du désir), mais aussi dans un sens collectif et politique : nous autres Berlinois de l'Est, nous autres prolétaires. Profiter du printemps, du soleil, de la tiédeur de l'air, c'est gratuit, et le parc dont il s'agit, est un «Volkspark » (appellation du XIX ${ }^{\mathrm{e}}$ siècle), le «Volkspark Friedrichshain » (sur les arrondissements Friedrichshain et Prenzlauerberg). C'est là que se trouve le « Mont-Klamott», appellation populaire («Klamott» au sens de « cailloux », « gravats») désignant le monticule constitué par les gravats déposés ici, à la fin de la guerre, par les « Trümmerfrauen », ces femmes qui déblayaient les ruines. Le sens politique impliqué par le Mont-Klamott (gravir le mont, c'est édifier le socialisme et la paix sur les ruines du capitalisme et de la guerre ${ }^{6}$ ) s'associe

5 Voir (entendre) dans beaucoup d'autres chansons ( So soll es sein - so wird es sein », « Bilanzballade im dreißigsten Jahr », etc.) les mêmes manifestations de vitalité animale (note tenue très longtemps, cris, beuglements) : le chanteur, d'abord, affirme, simplement, « performativement », un « je suis encore vivant» (ich lebe noch), et prouve que son souffle est bon, contre tous les appareils qui, littéralement, oppressent.

6 Décrivant l'ascension du «mont», Biermann se souvient peut-être de Pandaemonium germanicum de J. M. R. Lenz, satire de 1775 où l'on voit, dans la première scène, Goethe et Lenz gravir une espèce de Parnasse, Lenz avec difficulté et rampant dans les buissons, Goethe avec aisance et d'un bond. 
au sens privé : il s'agit, pour le couple, au cours d'une promenade à deux, par une belle après-midi, de respirer les effluves printaniers, et de se sentir fort et heureux par la grâce du renouveau plutôt que par l'effet des premières réalisations de l'État socialiste (le dernier refrain dit: «Wir dankten Marx und Gott»). Le premier couplet nomme les « Mietskasernen », et la sortie au parc et l'escalade sont une escapade dans la nature pour échapper aux laideurs de la ville. De ce point de vue, la chanson est comparable à « Die grüne Schwemme ». Mais «Die grüne Schwemme » forgeait l'image d'un " Abseits " élégiaque ou idyllique («Biedermeier»), l'image d'un lieu «poétique », non situé sur la carte et où le moi se retire de la vie publique et de la responsabilité sociale. Dans «Mont-Klamott», il n'y a pas de fuite " hors les murs ", la promenade est « dans les murs », elle ne quitte pas l'État et la ville, c'est de l'intérieur qu'elle les observe, et la chanson associe subtilement jusqu'au bout la dimension sensuelle-privée et la dimension politique et critique.

\section{Culture et contre-culture : «pros »}

Il y a une autre dimension à envisager, pour bien entendre et apprécier «Mont-Klamott». La chanson, en tant que « Ost- et Oster-(Frühlings-) Spaziergang » démarque le «Osterspaziergang » dans Faust ${ }^{7}$. La scène du Faust («Vor dem Tor ») décrit la sortie hors du cabinet de travail, et la promenade du savant docteur, accompagné de son «Famulus », et assistant aux danses et réjouissances du peuple ; une chanson, populaire et grivoise, se fait entendre ( ( Der Schäfer putzte sich zum Tanze»). Faust est salué par le peuple comme un sauveur, mais les témoignages de reconnaissance qu'il reçoit ne peuvent le satisfaire, il rêve de s'élever, comme l'alouette, vers la patrie céleste, il ne peut partager la joie printanière universelle (naturelle et populaire). La chanson de Biermann n'est pas écrite contre le poème classique, et d'ailleurs le Faust de Goethe (c'est-à-dire l'objet central de la culture allemande) enferme en lui-même son propre "contre " et propose du "populaire » et du contre-culturel, par exemple la chanson paysanne mentionnée ci-dessus, et d'autres chansons incluses dans le drame, ou encore, dans tout le poème de Goethe, l'alternance ou l'association du "Knittelvers " (le vers « populaire », peu " savant») et du pentamètre iambique. Ce mélange serait à comparer à ce qui, en France, au théâtre, représente le «classique» ou « canonique », c'est-à-dire l'équivalent de ce qu'est Faust dans la culture allemande. Le théâtre de Racine est uniment en alexandrins, le mètre autocrate ; la règle et le noble rejettent hors d'eux, dans le fruste et le roturier, ce qui n'est pas eux. L'analogie (la différence entre les deux cultures, et donc

7 «Der Winter lag im Sterben » se compare à « Der alte Winter in seiner Schwäche » de Faust ; «Wir lebten immer noch » à « Sie welkten hin, ich muß erleben / daß man die frechen Mörder lobt 》 (Faust, v. 1054-1055), etc. 
les deux " contre-cultures ») pourrait se poursuivre dans la comparaison des deux capitales : Berlin enferme des lacs, des terrains de sable, des forêts, comme si la colonisation et la culture n'avaient pas remplacé complètement la nature et le site primitif, comme si le sauvage subsistait dans le policé. De la même façon, dans la culture allemande, « chanson » (populaire ou naturelle) et «poème » (savant) ne s'opposent pas, comme ils le font en français ; le «Lied» appartient à la culture et à la contre-culture, ou, plutôt, ne se situe pas dans cette opposition, l'efface.

Ainsi, dans « Frühling auf dem Mont-Klamott», la critique politique et le lyrisme vitaliste sont-ils entrelacés. Dans le dernier couplet, le personnage masculin ( «ich ») est montré méditatif, contemplatif (et non pas actif), tandis que « die Dicke », entraînée par l'allégresse printanière, parle de paix, comme les bonzes du SED. Les deux promeneurs sont au sommet du monticule; que signifie, symboliquement, cette "victoire »? Peut-être l'espoir en l'édification du socialisme, peut-être la conquête de la culture, du Parnasse (Honecker parlait de la culture savante comme d'une montagne que les ouvriers devaient gravir et vaincre). Mais le «mont » qu'ils gravissent est une fausse montagne ; elle est faite des déblais du passé. Les deux personnages de la chanson font ce que fait, selon le premier vers de l'hymne de la RDA («Auferstanden aus Ruinen), l'État socialiste, ils renaissent (parce que c'est le printemps) au sommet du tas de ruines. Le silence de l'homme à la fín ( « ich hörte zu und schwieg ») est chargé de doutes et d'interrogations; c'est Heine, sans doute, que Biermann démarque ici ${ }^{8}$. La fin du couplet indique à la fois un repli dans l'intériorité, peut-être l'amertume et le découragement', et, malgré tout, et avec humour (le rouge du couchant et du socialisme recouvre l'Ouest), une sorte de profession de foi socialiste.

Le thème (c'est un thème du roman et de la poésie romantiques) de la sortie hors des portes de la ville, est repris et modifié ici par la chanson : il ne s'agit pas de retrouver dans la nature la liberté loin des contraintes sociales et des hommes : le couple reste " en ville », ne se "désolidarise " pas, ne s'évade pas. Mais il ne s'agit pas non plus du tout, comme il le faudrait dans le cadre du réalisme socialiste, de militer pour l'optimisme, la solidarité, la foi dans la patrie socialiste. Le couple, au sommet du monticule, est montré dans une aise et une solitude privées; il ne participe pas (pas plus que Faust) à une action collective ou à une fête populaire ${ }^{10}$. Dans 1'art de la chanson, cette

8 Voir, par exemple, le poème VII de « Die Heimkehr» dans le Buch der Lieder : «Wir saßen am Fischerhause / [...] Dic Mädehen horchten crnsthaft, / Und endlich sprach niemand $\operatorname{mehr} /[\ldots] »$.

9 L'amertume (《Bitterkcit ») à laquellc on cède ou que l'on sccouc, est un thème récurrent des poc̀mes et chansons de Bicrmann ; c'est un thème à la fois critique (l'amertume naît $d u$ constat que ee qui s'édifie n'est pas le socialisme désiré) et progressiste, car l'amertume surmontée se convertit en «encouragement», que l'on adresse à soi-même et aux autres (voir les chansons « Ermutigung », « Klcine Ermutigung 》, " Großc Ermutigung ») ; il s'agit d'inventer une fraternité libre à côté et contre la solidarité contrainte décidée par le SED.

10 « Frühling auf dem Mont-Klamott » n'est pas, dans ee sens, une chanson « populaire» comme le sont, dans le contexte français des années 30 , les chansons de guinguette, véritable 
oscillation entre public et privé peut se marquer par l'alternance des couplets et du refrain. Une chanson sans refrain, comme "Die grüne Schwemme", est, en puissance, une chanson "privée » appartenant tout entière à l'auteur, son apanage, non partagé. Le refrain est dans la chanson le moment collectif où tous peuvent faire «chorus » (la formule « tous au refrain » par laquelle le public est appelé à reprendre en chœur, est un rendez-vous, analogue à un 《tous dans la rue » ou « tous à la fête »); une chanson à refrain est toujours, en puissance, adressée, comme l'est de manière exemplaire dans le répertoire de Biermann «Ermutigung » ( $\mathrm{Du}$, lass dich nicht verhärten »), où c'est le «du » (tu, toi) lui-même qui fait refrain ${ }^{11}$.

Dans « Frühling auf dem Mont-Klamott», au refrain, où le mode majeur paraît s'installer franchement, le tempo et le chanteur s'animent, se secouent; mais le refrain est relativement bref, c'est comme s'il tournait court et comme si l'enjouement qu'il manifeste se modérait aussitôt et revenait vite à l'espoir plus mélangé et plus douteux qu'expriment les couplets. C'est la raison pour laquelle « Frühling auf dem Mont-Klamott» nous a paru, dans sa forme, caractéristique de la sorte d'opposition que Biermann a représentée dans le Berlin-Est des années $60:$ ce n'est pas l'opposition de l'artiste solitaire et retiré, mais c'est une opposition revendiquant, à l'intérieur même du socialisme, les droits lyriques de la personne privée à l'oisiveté, à la sensualité, au doute, à la critique, à la fraternité, à l'amitié. Le genre hybride de la chanson a convenu, de ce point de vue, à Biermann : car l'art de la chanson est dans ce « dialogue » au sens propre, c'est-à-dire dans ce partage de la parole entre un «moi » (celui des couplets) et un «nous » (celui du refrain), entre une absence (c'est la dimension lyrique ou romantique du «Lied ») et une présence (c'est la dimension militante et solidaire du « song »). C'est pourquoi la chanson de Biermann est un objet contre-culturel complexe. La préposition "contre » peut s'y comprendre avec les sens nombreux de la préposition "pros » (avec accusatif) du grec, le «pros » qui se rencontre au premier verset de l'Évangile de Jean : le «logos » était tourné vers, auprès de, chez, avec, en accompagnement de ( pros ») - Dieu ( « gegen » a quelques uns de ces sens : «gen Himmel»). Dans la chanson de Biermann (entendue comme Lied-chanson-song), la contre-culture (la protestation, le peuple, les opprimés) est " tournée vers » la culture et les deux dialoguent sur un pied d'égalité, comme font "Gedicht» et «Lied» dans la production de Biermann ; Biermann chanteur est toujours tourné vers Biermann poète et vers tous les poètes de la tradition culturelle. Le présent (ce qui s'incarne et se présente, entre en scène, «tritt auf ») se tourne vers ou séjourne chez - l'absent (ce qui ne se voit pas, ce qui est au-delà ou intime ou idéal). Jean dit : logos était auprès de Dieu, logos était Dieu. De la même manière : la contre-culture est la culture, et vice versa. Le sens du «contre »

genre contre-culturel ( «C'est un petit bal musette» dans le répertoire de Fréhel, par exemple) décrivant les réjouissances du «populo », explicitement opposées à celle des bourgeois.

11 «Ermutigung» a circulé clandestinement, dans les années 60, comme une espèce de contre-hymne de la RDA. 
revient au « est », est inscrite dans le verbe « être » qui note présence et absence, qui note d'une part l'action la plus immédiate et la plus pratique, la plus sensible et la plus chaleureuse ; et par ailleurs le désir le plus individuel et le plus secret. "Frühling auf dem Mont-Klamott» nous paraît représenter ce « est » auquel revient, comme dans Jean, I, 1, le «contre » de « contreculture »; ce besoin d'y être et d'en être, et d'autre part de s'absenter, de s'élever et de s'enlever. 